\title{
Erratum: T cell anergy is reversed by active Ras and is regulated by diacylglycerol kinase- $\alpha$
}

Yuanyuan Zha, Reinhard Marks, Allen W Ho, Amy C Peterson, Sujit Janardhan, Ian Brown, Kesavannair Praveen, Stacey Stang, James C Stone \& Thomas F Gajewski

Nature Immunology 7, 1166-1173 (2006); published online 8 October 2006; corrected after print 3 November 2006

In the version of this article initially published, the equal contribution of the third author was omitted. The error has been corrected in the HTML and PDF versions of the article.

\section{Erratum: A thymic pathway of mouse natural killer cell development} characterized by expression of GATA-3 and CD127

Christian A J Vosshenrich, Marcos E García-Ojeda, Sandrine I Samson-Villéger, Valerie Pasqualetto, Laurence Enault, Odile Richard-Le Goff, Erwan Corcuff, Delphine Guy-Grand, Benedita Rocha, Ana Cumano, Lars Rogge, Sophie Ezine \& James P Di Santo Nature Immunology 7, 1217-1224 (2006); corrected after print 3 November 2006

In the version of this article initially published, the symbols in the key of Figure 7a are incorrect. The filled ovals are Splenic; the filled diamonds are Thymic. The error has been corrected in the HTML and PDF versions of the article.

a

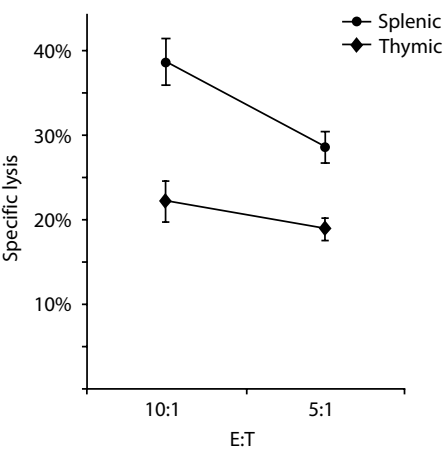

